\title{
EN BUSCA DE TESOROS BAJO EL MAR: INVENCIONES DE EQUIPOS PARA BUCEAR EN AMÉRICA
}

\author{
POR \\ NICOLÁS GARCÍA TAPIA \\ Universidad de Valladolid
}

Aunque la idea del hombre de sumergirse bajo el agua por tiempo ilimitado es muy antigua, la realización efectiva sólo se ha conseguido en los últimos tiempos. En el camino de la búsqueda de este sueño mültiples inventores han dejado sus esfuerzos y hasta sus vidas. Aqui se presentan aquellos que intentaron, en los siglos XVI y principios del XVII, sumergirse y buscar tesoros y perlas en los mares de los reinos hispánicos. Algunos llegaron a conseguir patentes por sus invenciones de equipos de bucear. Entre ellas están las campanas de Giuseppe Bono, de la que se presentan algunos modelos inéditos, recientemente hallados en el Archivo de Simancas. Pero el que destaca sobre todos los inventores es Jerónimo de Ayanz el primero que llegó a conseguir el sueño del hombre de poder estar bajo el agua durante un tiempo ilimitado.

\section{ANTECEDENTES DE LOS BUZOS}

El deseo de poder sumergirse bajo el agua ha formado siempre parte de la propia naturaleza del hombre, así como de su curiosidad y de la necesidad de buscar alimentos y cosas útiles bajo los ríos y el mar. Sin embargo, la limitada capacidad del aparato respiratorio humano le impide estar un tiempo prolongado bajo el agua; para ello, es indispensable la ayuda de ciertos instrumentos, con lo que la búsqueda de un equipo apropiado para bucear fue siempre una de las obsesiones de los inventores.

SIGLAS UTILIZADAS:

AGI: Archivo General de Indias, Sevilla.

AGS: Archivo General de Simacas.

AGP: Archivo General del Palacio Real, Madrid.

BNM: Biblioteca Nacional, Madrid. 
Es muy posible que los antiguos asirios utilizasen ya unos odres llenos de aire como ayuda para poder respirar bajo el agua. Varios bajorrelieves asirios del siglo IX a. C., conservados en el Museo Británico de Londres, representan unos hombres agarrados a un pellejo hinchado, que se dirigen por el agua al asalto de una fortaleza defendida por unos arqueros. Se ha interpretado esta escena como la de unos nadadores que se sirven de flotadores para atravesar el río, como todavía se hace en algunos lugares de Asia. No obstante, examinando atentamente los relieves del Museo Británico, puede apreciarse que los personajes están bajo el agua y aspiran por la boca el aire de unas vejigas, lo que podríamos interpretar como el primer antecedente conocido de un equipo de bucear.

En época romana, los buzos son descritos por Vegecio en su obra De re militari. A finales de la Edad Media y comienzos del Renacimiento, aparecen algunos equipos de bucear, más bien fantásticos e impracticables. Por ejemplo, a finales del siglo XIV y principios del siglo XV, se representan algunos en el manuscrito de Kieser y en el llamado Anónimo de la guerra husita. Jacopo Mariano, «il Taccola», presentó hacia 1440 un curioso traje de buzo que se unía a través de un tubo a la superficie para poder respirar por él. En ninguno de estos aparatos para bucear estaba prevista la indispensable renovación del aire, sin la cual el hombre acaba ahogándose al cabo de poco tiempo.

Leonardo da Vinci también se ocupó de los equipos para bucear, con diseños que son casi modernos en apariencia. Su principal aplicación era para hundir buques enemigos. En uno de ellos, había una especie de cúpula flotante de la que partían unos conductos hacia una máscara provista de válvulas para inhalar y expulsar el aire, que debía adaptarse a la cara del buceador. Otro presentaba un traje de bucear con una armadura para proteger el pecho del buzo de la presión del agua. Incluso hay un boceto que se ha interpretado como una especie de submarino. A pesar de lo sorprendente de estos dibujos, la falta de una descripción precisa, y el hecho de que las notas de Leonardo no llegaran a difundirse, hace pensar que se trataba de simples ideas que no llegaron a concretarse en aparatos prácticos. Sin embargo, es indudable que, a finales del siglo XV y a principios del XVI, había ya en Italia algunos inventores que se dedicaron a hacer equipos de buceo, aunque la seguridad de 
éstos era muy escasa y el tiempo que permitían permanecer bajo el agua muy limitado (1).

\section{INVENTOS DE EQUIPOS DE BUCEAR PRESENTADOS EN ESPAÑA EN EL SIGLO XVI}

El ascenso de España a primera potencia política, militar y naval en el siglo XVI, condujo a que los inventores de equipos de buceo ofreciesen sus servicios a los monarcas españoles. En algunos manuscritos españoles de la época, como en el hasta ahora erróneamente atribuido a Juanelo Turriano, conocido como Los veintiún libros de los ingenios, su autor, el aragonés Pedro Juan de Lastanosa, expone algunos equipos de bucear semejantes a los italianos antes descritos (2).

Lo cierto es que, con instrumentos o sin ellos, los buzos buscaban perlas y coral bajo el mar, y realizaban operaciones de salvamento de mercancías de barcos hundidos. Tal fue por ejemplo el caso de unos buzos, vecinos de Cádiz y de Vejer que, a mediados del siglo XVI, habían conseguido salvar las mercancías de una nao que se había perdido por completo camino de Lisboa (3).

Uno de los primeros inventores españoles de instrumentos para buzos fue el hidalgo toledano Blasco de Garay, más conocido en cambio por sus navíos movidos por ruedas de paletas que durante algún tiempo se confundieron con la invención del primer barco de vapor (4). En el año 1539 propuso al emperador Carlos I una serie de invenciones entre la que se encontraba la siguiente: Un ingenio para que cualquier hombre pueda estar debajo del agua todo el tiempo que quisiere, tan descansadamente

(1) Varias historias de la tecnología tratan sobre diversos aspectos de los equipos de bucear. Un resumen de la evolución de los mismos en: Nicolás García TAPIA, Patentes de invención españolas en el Siglo de Oro, Madrid, 1990, págs. 9094.

(2) "Los veinte y un libros de los ingenios y máquinas de Juanelo...", BNM, Ms. 3372-3376. Ed. Madrid, 1983, prólogo de José Antonio Garcfa-Diego. La cuestión de la autoria en Nicolás GARCía TAPIA, Pedro Juan de Lastanosa. El autor aragonés de "Los veintiún libros de los ingenios", Huesca, 1990. El estudio del manuscrito en Nicolás García TAPIA, "Los veintiún libros de los ingenios y máquinas de Juanelo", atribuidos a Pedro Juan de Lastanosa, Diputación General de Aragón, en prensa.

(3) AGS, Cámara de Castilla, leg. 443, fol. 25.

(4) García Tapia, Patentes [1] págs. 16-19. 
como encima (5). Por desgracia no conocemos en qué consistía el sistema, ni si alguien lo probó. Es la primera vez, que sepamos, que se habla de permanecer bajo el agua sin la limitación de tiempo impuesta por los instrumentos hasta entonces conocidos, en los que no había renovación de aire.

Otro español que pretendía haber inventado un aparato de buceo capaz de funcionar bajo el agua por tiempo indefinido, fue Hernán Ruiz de Rozas, natural de Espinosa de los Monteros (Burgos), que había hecho un ingenio en el Monasterio de San Lorenzo de el Escorial para colocar la vela de la cruz del chapitel de una de las torres, sin necesidad de andamios. El 2 de enero de 1589, propuso un ingenio para que los «busanos" (los buzos) estén bajo el agua todo el tiempo que quieran. Como no tenía dinero para poder terminar su invento $\mathrm{y}$ whacer otro curioso $\mathrm{y}$ necesarion, se lo pidió a Felipe II, ofreciendo como única garantía el que «le corten la cabeza si no saliere con lo que dice» (6). Ignoramos si consiguió el dinero para hacer la prueba, así como si encontró un kbusano» que se sometiese a ella, arriesgando su vida además de la cabeza del inventor.

Varios inventores extranjeros también ofrecieron a los monarcas españoles sus inventos para bucear. Uno de ellos fue Martín Altman, un relojero alemán que vino a servir en su oficio a Carlos I en 1555 y luego pasó a construir ingenios para la artillería con un salario de 25 escudos al mes. Años más tarde, envió a Felipe II una relación de sus invenciones, principalmente destinadas a la artillería, pero entre las que también había un equipo de bucear, esta vez para estar bajo el agua por tiempo limitado hasta doce horas, cómodamente, incluso a profundidades de veinte o treinta brazas. Podía asi el buzo ver lo que había bajo el agua, al objeto de barrenar un buque, o sacar perlas, coral, o los aparejos y tesoros de un barco hundido. Después de tres años tratando de convencer al rey, gastando en ello su fortuna, pide que le dé respuesta o le deje uirse a descansar", consiguiendo finalmente, en 1589, que se le dé autorización para que se hagan las pruebas de sus invenciones, de las que no tenemos constancia de sus resultados (7).

Otro inventor llegado a España para probar fortuna con sus

(5) AGS, Guerra Antigua, leg. 14, fol. 22.

(6) Idem. leg. 267, fol. 70 y leg. 272, fol. 5. García TAPIA, Patentes. [1] pág. 30 y Del dios del fuego a la máquina de vapor. La introducción de la técnica en Hispanoamérica, Valladolid, 1992, págs. 310-311.

(7) AGS. Guerra Antigua, leg. 262, fol. 301; leg. 266, fols. 175 y ss.; leg. 268, fol. 35. Garcia Tapia, Patentes [1], págs. 23 y 24. 
inventos fue uno que en los documentos españoles se denomina Beneditto Pelletiero (o Peliter otras veces). Era natural de Saboya y se presentó como kingeniero de la batalla naval", ofreciendo a Felipe II, en 1589, una serie de invenciones de las que no quiso revelar el "secreto" hasta que no se hiciese la prueba ante el Rey, pagándole los costes de las mismas que ascenderían a unos 3.000 ducados. Además pedía que se le concediese un cargo y se le compensase con 500 ducados por el servicio. Entre los inventos estaba un aparato, para que uno o varios hombres armados puedan estar bajo un río un día entero o dos, sin mojarse ni peligrar (8). Aunque había aumentado el tiempo prometido de permanencia bajo el agua, no creemos que Felipe II accediese a las desmesuradas exigencias del saboyano. Al menos, no nos consta que se expediese nunca ningún privilegio de este tipo.

\section{INVENTOS DE EQUIPOS DE BUCEAR DESTINADOS A AMÉRICA}

Si las actividades de los buzos revestían una gran importancia en Europa para el rescate de embarcaciones, búsqueda de coral y otras riquezas submarinas, la Carrera de las Indias hizo que el interés por el fondo del mar fuera aún mayor. Era precisamente en las costas americanas donde se producía el mayor número de pérdidas de navíos, dado que en alta mar los peligros eran menores y, en todo caso, las dificultades de llegar hasta la profundidad del barco hacían inútiles los trabajos de búsqueda y rescate de su contenido, por lo que las operaciones de buceo en busca de tesoros perdidos se limitaban a los lugares poco profundos de las costas.

Otra actividad, de gran importancia para los buzos, era la búsqueda de perlas en los ricos ostrales de las costas americanas. Desde los primeros viajes se descubrieron y explotaron estas "granjerías de perlas". Así, entre 1499 y 1500, el viaje de Pedro Alonso Niño y Cristóbal Guerra resultó de un gran interés por la riqueza perlífera de la isla Margarita, que iba a tener mucha repercusión en los años siguientes. Dada la dificultad de respirar un tiempo prolongado bajo el agua, se produjeron un número elevado de muertes entre los indios buceadores, por lo que en las ordenanzas laborales de principios del siglo XVII se prohibió el trabajo forzoso de los indígenas en las "pesquerías» de perlas,

(8) AGS. Guerra Antigua, leg. 264, fols. 293-296; leg. 307, fol. 110; leg. 312, fol. 153. García TaPia, Patentes [1], págs. 30 y 31. 
siendo reemplazados por negros. A éstos se los llevaban en canoas hasta los ostrales, donde se sumergian en busca de las perlas. El negocio era muy próspero para los "canoeros" o dueños de canoas, a pesar del impuesto del quinto real que debían entregar para la Corona. Pero los lugares ricos en perlas estaban cada vez a mayor profundidad, de ahi la necesidad de resistir los buceadores más tiempo bajo el agua sometidos a una mayor presión, lo que agotaba sus fuerzas. El interés por encontrar sistemas para ayudar a respirar a los buzos era vital, y no pocos inventores, tanto en España como en América, dirigieron su interés a descubrir equipos de buceo eficientes.

Ya desde mediados del siglo XVI, se extendieron privilegios de invención de equipos de bucear con destino a América. Estos se tramitaban a través del Consejo de Indias el que, una vez examinados por expertos, dictaminaba la conveniencia de otorgar la correspondiente patente de invención para ser explotada por su poseedor, en exclusiva, por un número de tiempo variable. Es así cómo, en 1556, se concedió al inventor Pedro de Herrera un privilegio para usar un ingenio destinado a sacar oro y perlas del fondo del mar (9). Según otra cédula fechada en Valladolid el 8 de agosto de 1568, se concedió un privilegio a Hernando Maldonado para que usara en exclusiva, durante cuatro años, un artificio que había inventado para sacar perlas, piedras preciosas, oro y plata de los ríos. Fue presentado ante el Consejo de Indias, que amplió su patente para los territorios americanos, a condición de entregar la quinta parte de lo descubierto (10).

La invención era a veces explotada entre varias personas. Diego de Lira, que era vecino de Málaga, y Antonio de Lima, de México, formaron, junto a Antonio Luis de Cabrera, una compañía comercial para explotar una pesquería de perlas, basándose en la invención de un ingenio para sumergirse, cuya licencia de patente habían obtenido en 1568 del Consejo de Indias. La concesión se otorgó por 16 años y conllevaba los privilegios de exención de impuestos sobre los materiales necesarios para construir los ingenios de bucear, la autorización para llevar hasta trece operarios a América y el permiso para introducir cien esclavos negros buceadores. En compensación, se comprometían a entregar a la Corona

(9) AGI, Indiferente General, leg. 425. Pablo E. Pérez-Mallaina Bueno, "Los inventos llevados de España a América en la segunda mitad del siglo XVI"; Cuadernos de Investigación Histórica, 7, 1983, pág. 41.

(10) AGI, Indiferente General, leg. 423, fol. 153. 
la mitad de los tesoros hundidos que rescatasen con sus instrumentos y la cuarta parte de las perlas halladas (11).

Las innovaciones en este campo continuaron. En 1573, Francisco Soler hizo «con su industria y trabajo ... un cierto ingenio diferente de los que se han descubierto por otras personas, con el cual, con mucha facilidad, se puede entrar debajo del agua y en el fondo de ella y sacar cualquier tesoro que en ella hayaw. Por este motivo solicitó del Consejo de Indias un privilegio para explotarlo en exclusiva. Lo cual, examinado por dicho Consejo, se consideró que era merecedor de ello por el tiempo de diez años, bajo una sanción de $\mathbf{5 0 . 0 0 0} \mathrm{mrs}$. a los que lo usasen sin la correspondiente autorización y con la obligación de entregar la quinta parte de lo descubierto por el inventor o las personas por él designadas (12).

El perfeccionamiento de los ingenios de bucear continuó de la mano de otros inventores. El 21 de octubre de 1576, Cristóbal de Maldonado presentó un artificio «que sirve de pescar y sacar perlas, oro y plata y cosas de navios perdidos y otras cualesquiera que están debajo del agua, en el cual se podrá andar debajo de ella sin limitación de tiempo y obrar con las manos fuera del dicho ingenio y hacer otros efectos en la mar, ríos y lagunas» (13).

Escasos son los datos que proporciona Maldonado de este artefacto que permite estar por tiempo ilimitado bajo el agua y además andar y tener las manos libres para trabajar. Dice que «es diferente a todos los que hasta ahora se han hecho" y parece indicar que tiene un dispositivo de entrada y salida de aire para respirar, a juzgar por lo que describe.

El cual dicho ingenio ha de tener dos respiraderos o más que salen fuera del agua, por uno de los cuales se reciba aire y lo comunica en el mesmo ingenio y lo hecha por otro, o otros diferentes del, por donde los recibió, y que esto se entiende siendo el dicho ingenio cerrado por todas partes sino por los dichos respiraderos, y que siendo abierto, recibiendo por uno de los dichos respiraderos aire, los despida por el agua (14).

De esto se puede deducir que no se trata de la conocida campana de bucear, que otros inventores, como veremos inmediatamente, pretendían hacer suya, sino de un recinto cerrado

(11) Pérez-Mallaina [9], pág. 41. García Tapia, [6], pág. 298.

(12) AGI, Indiferente General, leg. 426, fols. 256-257.

(13) Pérez-Mallaina [9], págs. 41-42. Garcia TaPia, [6], págs. 301-302.

(14) AGS, Cámara de Castilla, leg. 532, fol. 134. 
por todas las partes, donde se introducía el buzo, dejándole libre las manos y las piernas. El hombre podía recibir aire por un conducto comunicado con el aparato y expulsarlo al exterior, pero no se habla de instrumentos para introducir el aire, ni de válvulas para regular la entrada y la expulsión del aire va directamente al agua, con lo que se necesitaría una válvula de no retorno para evitar que el líquido penetre en el interior del recinto. No sabemos si se probó el instrumento, ni si se añadieron estos elementos que faltan, pero lo cierto es que se le concedió un privilegio por parte del Consejo de Indias para usar el ingenio de bucear por un período de veinte años, con la condición de entregar el quinto del beneficio encontrado con el mismo.

De ninguna de las invenciones de equipos de bucear que hemos visto hasta ahora conservamos dibujo alguno que nos pueda orientar sobre su construcción y sobre la posibilidad de su funcionamiento. Tampoco nos consta que hayan sido probadas, con lo que no sabemos si cumplirían las condiciones de estar bajo el agua durante tiempos tan prolongados como prometen. A juzgar por lo poco que se dice en los documentos, nos tememos que un hombre no podría estar allí más de unos veinte minutos, que era el tiempo que permitían entonces las campanas de buceo.

Sin embargo, de estas campanas de bucear se han conservado unos dibujos del italiano Giuseppe Bono, alguno de ellos desconocido, por lo que vamos a dedicarlos una mayor atención.

\section{GIUSEPPE BONO Y SU CAMPANA DE BUCEAR}

Giuseppe Bono era un hidalgo siciliano, natural de Palermo, que fue a Florencia al servicio de Cosme de Medicis en calidad de "comisario general de todas las armas" de la república florentina. El 30 de octubre del 1570, el Gran Duque de Toscana le concedió un privilegio o patente por invención por un ingenio para pescar coral y otras cosas del fondo del mar en forma de "un vaso casi de hechura de orinal», con el que dice que había renovado la pesca cerca de Montenegro en el mar Tirreno. El privilegio era por un período de diez años y cubría la zona del Estado de Florencia. La obligación de Bono era entregar todo el coral que sacare para llevarlo «a Pisa o a Florencia y no a otra parte alguna para que se pueda refinar y dar color por nuestros oficiales", pagando el diezmo al veedor con destino a la república toscana (15).

(15) AGI, Indiferente General, leg. 426, fols. 2-5. 
No sabemos las razones por las cuales en 1581 vino a España, perdiendo según él una renta de 400 ducados, para ofrecerse al servicio de Felipe II, al que propuso una serie de secretos militares que pertenecían a su anterior cargo de comisario de armas de Florencia. Sin embargo, es recibido con cierta desconfianza en la Corte de Felipe II. Según los consejeros reales, por boca del secretario de Felipe II, Francés de Álava, estos secretos militares consistían en «ingenios de fuego, unos útiles y otros inútiles, (pero que) son casos que otros muchos hombres que andan por el mundo y están al servicio de Vuestra Majestad saben hacern.

Otro ofrecimiento de Bono era dragar los ríos, entre ellos el Guadalquivir en Sevilla, ya que impedía la navegación, así como sacar de allí los barcos hundidos y los objetos del fondo de todos los ríos navegables, como el Tajo en Lisboa, donde había de 400 a 500 áncoras perdidas. También se ofrecía para hacer máquinas de acuñar monedas, aparatos para destilar diferentes líquidos alquímicos, hornillos de fundición y, en general, decía que era capaz de hacer «todo lo que fuera necesario". Hasta tal punto debía prometer cosas poco verosímiles, que Francés de Álava concluye diciendo que «lo peor que siento en él es la mucha confianza que tiene en todas las cosas que se le proponen", y el propio Felipe II, corroborando su calificativo de «Prudente», comenta que «no es bien que vaya a Sevilla sin que estemos muy ciertos de que hará lo que dice, porque podría gastar mucho en balde y por esto será bien que primero se examine muy bien la forma que dice" (16).

Entre las invenciones propuestas por Bono, la más interesante -aparte de sus campanas de bucear de las que nos ocuparemos a continuación - es un molino centrífugo, que merece la pena resaltar por ser algo aún inédito $\mathrm{y}$ por poderse considerar un precedente de los reguladores centrífugos difundidos por Watt en sus máquinas de vapor, (Fig. 1). Lo que es propiamente el molino tiene poco de original: un eje vertical con una gran rueda dentada, que a su vez mueve otras más pequeñas para hacer girar las piedras de moler a la velocidad adecuada. Lo más novedoso es el volante, con una especie de martillos colgantes en toda su periferia, que se encuentran en la parte superior. Bono los describe así: «Los volantes que están encima de la piedra se ensanchan y se encoge: son diez y ocho y pesan diez libras cada uno" (17).

(16) AGS, Guerra Antigua, leg. 109, fol. 344. GARcía TAPIA, [1], pág. 28 y [6], págs. 307-308. 35.

(17) AGS, Cámara de Castilla, leg. 594, fol. 6. Mapas, Planos y Dibujos, LVII- 
En efecto, al girar las muelas, los pesos que cuelgan del volante tienden a levantarse por efecto de la fuerza centrífuga, lo que contribuye a regular la velocidad y almacenar la energía, ayudando al trabajo de los bueyes. Los pesos hacen así el efecto de las bolas del llamado regulador de Watt del siglo XVIII, cuando se elevan por efecto del giro, aunque, en este último caso, su función era aún más compleja ya que servían para regular la entrada del vapor. Por tan singular invención, Bono solicitó en 1585 un privilegio por 25 años para todos los reinos españoles, incluidos los de América. Relacionado también con el molino de cereales, está otro suyo para poder conservar el trigo en los silos, por el que igualmente solicitó privilegio por invención (18).

Pero, sin duda, las más curiosas invenciones del siciliano son las campanas de buceo, más que por su novedad, por el hecho de que estas patentes de invención van acompañadas de una detallada descripción con sus dibujos, lo que nos permite conocer cómo eran estos sistemas de buceo en el siglo XVI.

Ya hemos dicho que Bono había obtenido un privilegio en Florencia por la invención de una campana para sumergirse, pero que deseaba mejorarla e introducirla en España y en las Indias para el rescate de los tesoros de los barcos hundidos y para la búsqueda de perlas. En 1583 pidió naturalizarse en España ya que quería upasar a las Indias donde en la pesquería de las perlas esperaba hacer mucho efecto de que a la hacienda de Vuestra Majestad y al bien público resultaría gran provecho, [pero] el Consejo de Indias se lo estorba, excluyéndole por extranjero de estos reinos" (19). Después de reiterar su petición porque "ha muchos años que reside en estos reinos y desea vivir siempre en ellos como natural de estos" (20), Bono consigue naturalizarse el 14 de agosto de 1583. Según el Consejo, el ingenio para rescatar las perlas y tesoros submarinos «era de más provecho para el servicio de Vuestra Majestad y para todo, en las Indias que en otra parte» (21). Desde entonces, Giuseppe españoliza su nombre y aparece denominado en los documentos españoles como «Jusepe Bono" o bien como "José Bono".

Presentamos aquí el dibujo conservado en el Archivo General de Simancas de la campana de bucear con la que Bono hizo sus

(18) Idem, Cámara de Castilla, leg. 595, fol. 23.

(19) AGI, Indiferente General, leg. 426, fol. 16.

(20) AGS, Cámara de Castilla, leg. 549, fol. 20.

(21) AGI, Indiferente General, leg. 426, fol. 16. 


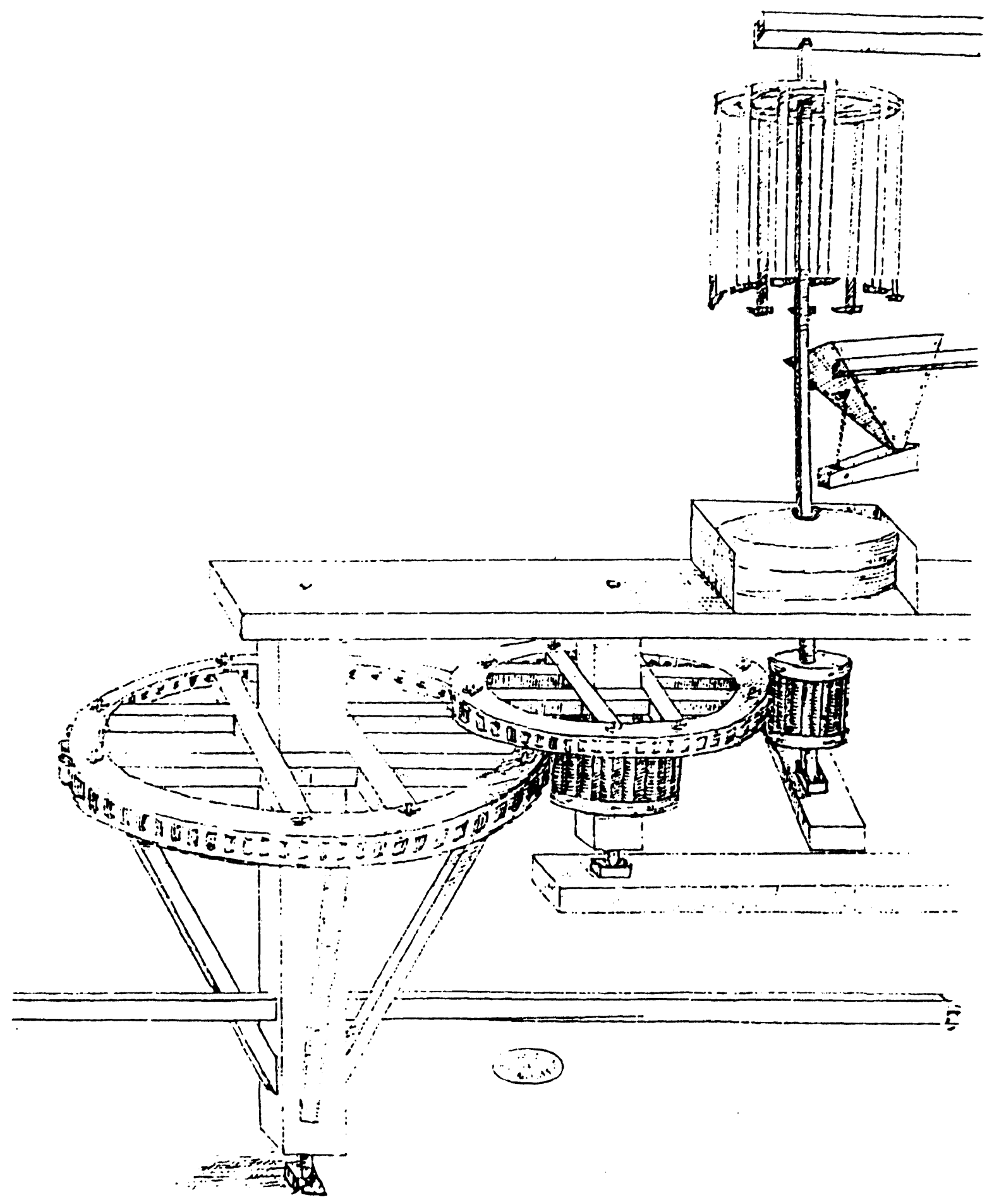

FIG. 1. Giuseppe Bono. Molino con regulador centrífugo. (Archivo General de Simancas). 


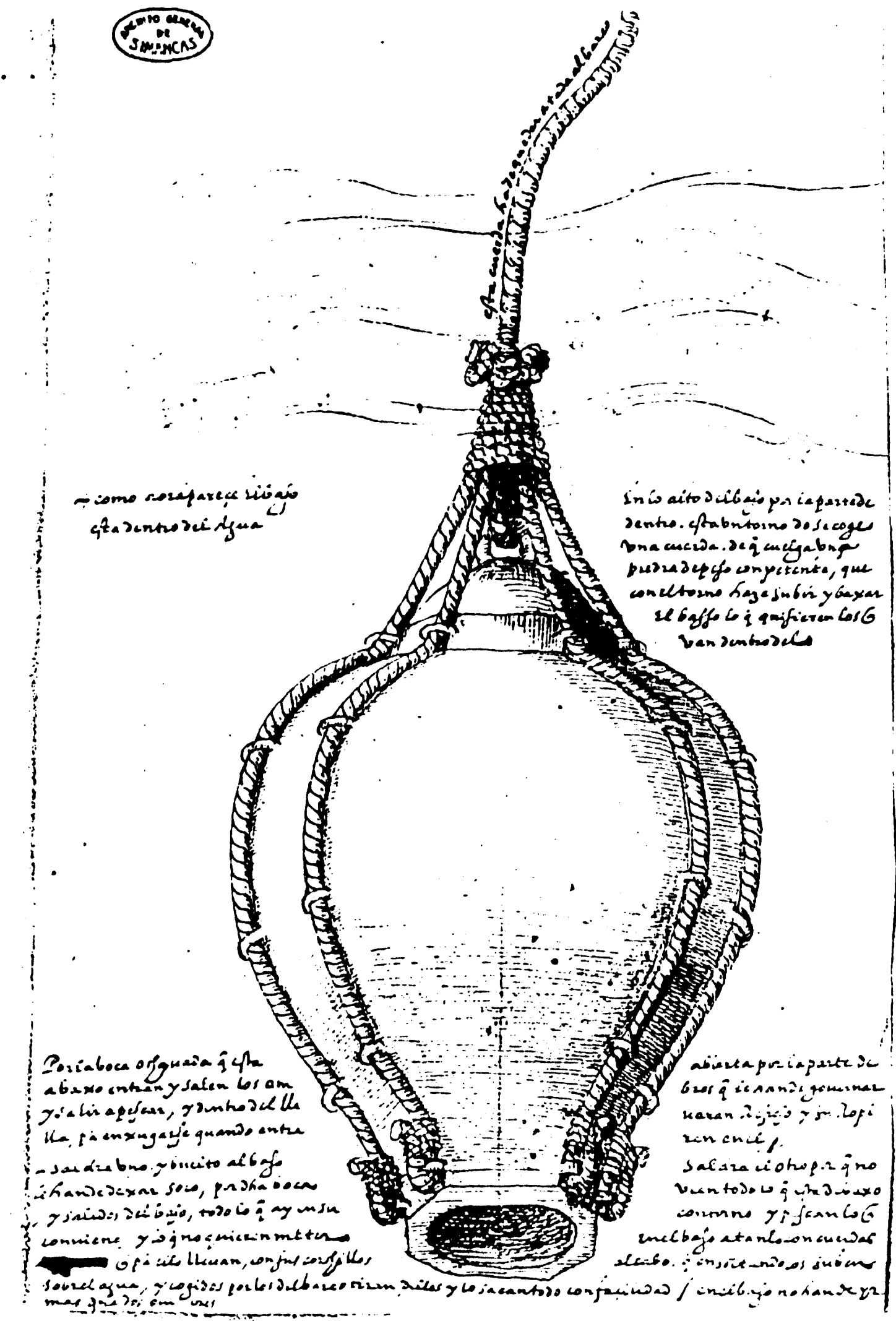

Fig. 2. Giuseppe Bono. Campana de bucear de madera. (Archivo General de Simancas). 


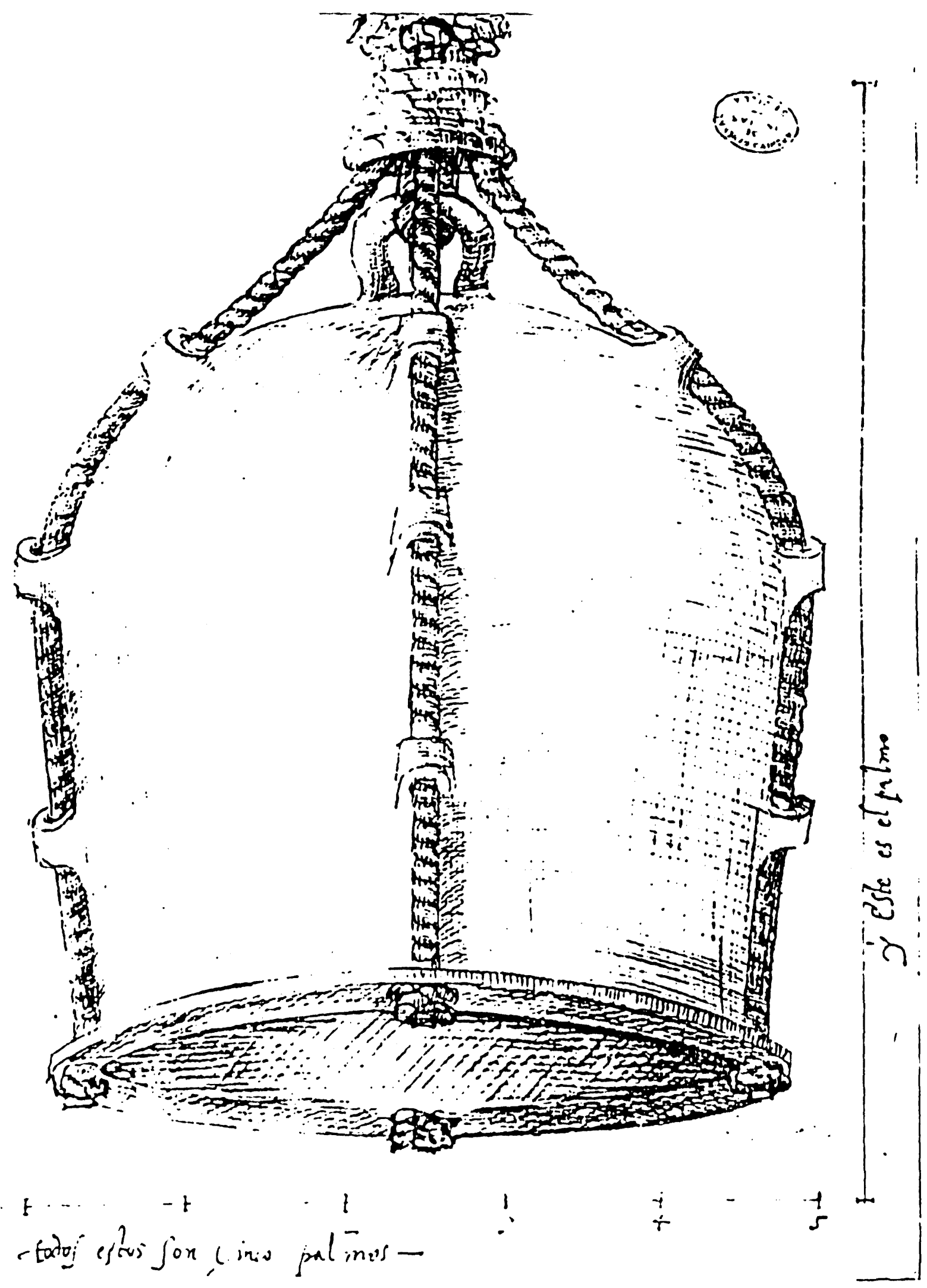

FIG. 3. Giuseppe Bono. Campana de bucear metálica. (Archivo General de Indias de Sevilla). 
primeros experimentos en Espafa (22). (Fig. 2). Como se explica en la documentación que acompaña al dibujo, el instrumento es de madera y tiene el utalle de un frascón ochavado" (o "de un orinal» según otros documentos) sin ningún respiradero y se introduce en el agua boca abajo. El aparato se sujeta al barco con una gruesa maroma y queda colgado dentro del agua. Para poder subirlo y bajarlo, por la parte de dentro hay un torno en el que se enrolla una cuerda de la que cuelga una piedra con el peso necesario, la cual, al subir o bajar, permite variar la profundidad a la que se sumerge la campana. Por la boca ochavada, que está en la parte de abajo, entran y salen los hombres que han de gobernar la campana y salir a pescar, "y dentro de ella llevarán refresco y su ropilla para enxugarse». Los dos hombres deberán turnarse, uno saliendo y otro entrando, ya que sólo hay aire para uno en el interior. Mientras tenga aliento, el de fuera puede pescar y faenar bajo el agua, luego entrará en la campana y será sustituido por el otro (23). Lo que no se dice es que esta operación no puede repetirse indefinidamente, ya que acabaría por viciarse el aire del interior de la campana, haciéndose irrespirable.

José Bono hace la petición de privilegio para usar este aparato por un período de treinta años, pero sólo se le concede por diez, en una primera cédula expedida el 10 de enero de 1582 (24). Inmediatamente comienza Bono a hacer pruebas de su instrumento en Sevilla y en Lisboa. De ellos da testimonio el secretario de Felipe II, Antonio de Eraso, que

vio ponelle junto a la proa de un navío de alto bordo, y que le cargaron con ciertas pesas de plomo amarradas con unas cuerdas y que le dexaron hundir en el agua, a su paresçer más que estado y medio; y que se ha hecho a la mar un hombre y entró, según dixo y allí se entendió por cierto, en el vaso del dicho ingenio, y estuvo metido en él más de un buen cuarto de hora, al cabo del cual salió, y refirió que, porque no estaba bien estanco ni tapado el dicho ingenio, y tener algunas aberturas por donde se salía el aire, iba entrando alguna agua en poca cantidad (25).

(22) AGS, Cámara de Castilla, leg. 532, fol. 174.

(23) AGI, Indiferente General, leg. 426, fol. 17.

(24) AGS, Cámara de Castilla, leg. 532, fol. 174.

(25) AGI, Indiferente General, leg. 426, fol. 7. 
El experimento se repitió en otras ocasiones, "con el dicho vaso en el río de Lisboa muchas veces..., entrando, saliendo, y estando dentro de él debaxo del agua grandísimo espacio los nadadores, sin pasar trabajo ni peligro alguno, sino con mucho sosiego, aunque el vaso no estaba bien estanco, por ser de madera y mal hecho" (26).

Los defectos de la campana de madera son reconocidos por el propio Bono, quien ordenó hacer una campana de metal de una pieza. Esta es la que corresponde al dibujo que se conserva en el Archivo General de Indias de Sevilla, en el que se ve una campana metálica de casi cinco palmos (Fig. 3) de diámetro, con una argolla y unas guías para pasar unas cuerdas con las que se sostiene en alto (27). Así se pueden hacer diversos trabajos bajo el agua con cierta seguridad, como el rescatar unas áncoras que obstruían el paso a las embarcaciones que entraban en Lisboa, donde había entre 400 a 500 áncoras perdidas. Con su campana de bucear, Bono pudo sacar seis de ellas que estaban en el fondo del río, a una profundidad entre once y doce pasos según testificó, el 23 de septiembre de 1583, el licenciado Martín de Aranda (28). El inventor había propuesto también hacer la misma operación en Sevilla, dragando además la entrada del Guadalquivir, que impedía la navegación, y sacando de allí los barcos hundidos. Si esto tenía éxito, Bono pensaba hacerlo en todos los ríos navegable (29).

Con esta campana de metal se repitieron los experimentos en Lisboa. El 12 de noviembre de 1583, el Cardenal Archiduque

vio un día de estos un vaso de metal hecho en forma de campana por invención de Josepe Bono, en este río de Lisboa, en el cual entraron dos hombres y estuvieron en el dicho vaso debaxo del agua más de un cuarto de hora, y dixeron que estarían en él todo el tiempo que quisieren. Viólos después salir y volver a entrar, y sacar lo que estaba en el hondo de la mar, y esto sin peligro ni pesadumbre de los que andan en él, según ellos lo afirman (30).

En consecuencia, este sistema parecía muy provechoso para la finalidad de buscar tesoros, coral y perlas en el fondo del mar, motivo por el cual a Bono se le concedió, e 1583, un privilegio

(26) Idem., fol. 6.

(27) AGI, Mapas y Planos, Ingenios y Máquinas, $n^{2} 5$.

(28) Idem., Indiferente General, leg. 426, fol. 8.

(29) AGS, Guerra Antigua, leg. 109, fol. 344. García TaPia, Patentes, [1], pág. 28 y Del dios del fuego, [6], págs. 307-308.

(30) AGI, Indiferente General, leg. 426, fol. 3. 
para poder explotar también su invención en unuestros reinos y señorios, en toda agua salada y dulce», especialmente en las Indias y más concretamente, en la isla Margarita, para explotar la abundante riqueza perlífera (31). Esta patente de invención se renovó en 1586, ya que Bono alegó que había extraviado la que le habian dado anteriormente (32).

La campana de bucear de Giuseppe Bono no se diferencia, en realidad, de otras conocidas a través de los tratados técnicos de la época, sobre todo para las aplicaciones militares, como las de Taccola, Francesco di Giorgio Martini y Leonardo da Vinci. A pesar de la mejora que supuso el hacer la campana metálica y de una sola pieza, evitando las filtraciones de agua, era imposible estar más de veinte minutos en su interior, sin renovar el aire. Bono no había previsto un sistema para expulsar el aire viciado y sustituirlo por aire limpio procedente del exterior. Los testimonios de sus experimentos, aunque favorables, siempre dicen que los buzos estuvieron bajo el agua algo más de un cuarto de hora. El sueño de resistir un hombre en el fondo submarino por tiempo indefinido aún no se había cumplido.

\section{LAS PRECURSORAS INVENCIONES DE JERÓNIMO DE AYANZ}

El deseo del hombre de poder estar bajo el agua sin peligro y sin mayores molestias por tiempo ilimitado, se cumpliría en agosto de 1602, en el río Pisuerga en Valladolid, ante el rey Felipe III, toda su Corte y una multitud asombrada. El promotor de esta proeza describe así el acontecimiento:

Su Majestad quiso ver lo que parecía más dificultoso, que era poder un hombre trabajar debajo del agua espacio de tiempo, así, por agosto del año pasado de 1602 , fue con sus galeras por el río de esta ciudad al jardín de don Antonio de Toledo, donde hubo mucha gente. Eché un hombre debajo del agua, y al cabo de una hora le mandó salir Su Majestad, y aunque respondió debajo del agua que no quería salir tan presto porque se hallaba bien, tornó Su Majestad a mandarle que saliese. El cual dijo que podría estar debajo del agua todo el tiempo que pudiese sufrir y sustentar la frialdad de ella y la hambre. Quisiera hacer esta prueba por otros caminos que causarán más admiración, y satisfacer con la que Su Majestad más gustara de

(31) AGS, Cámara de Castilla, leg. 532, fol. 174.

(32) Idem, leg. 607, fol. 8. 
las demás de los pareceres, como se lo dije y se los di. Respondió que de allí a cuatro días que guardase la memoria de las máquinas que le había dado hasta que las quisiese ver, pues por sus ocupaciones no lo hacía entonces (33).

El inventor de los revolucionarios sistemas de buceo permitieron este acontecimiento fue Jerónimo de Ayanz y Beaumont, uno de los grandes genios españoles desconocidos a los cuales no se ha hecho aún justicia. El olvido de la historia de la tecnología española, aún no reconocida como disciplina académica, ha hecho que hombres de la talla de este inventor queden enterrados en los documentos de archivo, sin que nadie se preocupe de investigar, con la profundidad requerida, la valía de sus descubrimientos.

Jerónimo de Ayanz nació en Pamplona en 1553, descendiente de las familias Ayanz y Beaumont, ligadas a la nobleza navarra. Su vida fue muy intensa y abarcó variados campos de actividad. Estuvo desde niño, como paje, al servicio de Felipe II y luego se dedicó a la milicia, participando en diversas campañas, destacando en las de las islas Terceiras. Obtuvo la reputación de hombre de extraordinario valor, ingenio y fuerza, lo que le valió la admiración de los que le conocieron, ya que, al parecer, era capaz de doblar las lanzas de los enemigos, arrancar rejas, detener caballos al galope y otras proezas que merecieron ser cantadas por los sonetos del propio Lope de Vega. En una ocasión salvó la vida de Felipe II en un atentado, quien le tuvo siempre en alta estima, otorgándole dos encomiendas de la Orden de Calatrava, de la que era caballero, así como numerosos cargos en su servicio (34). La extraordinaria fuerza de Ayanz era compatible con otras habilidades de naturaleza muy diferente. Así, era aficionado a la música y al canto, siendo un buen compositor y poseía una magnífica voz de bajo, a juicio de sus contemporáneos. En otro orden de cosas, era diestro con el pincel y, aunque no conocemos sus cuadros, figura como un buen pintor en los repertorios de los artistas de la época (35).

(33) Respuesta de don Jerónimo de Ayanz AGS, Contadurías Generales, leg. 852, sin foliar. Sobre este episodio en el río Pisuerga véase, Nicolás GaRcía TAPIA, Técnica y poder en Castilla durante los siglos XVI y XVII, Salamanca, 1989, págs. 209-213.

(34) García TAPIA, [1], págs. 53-56. Estamos preparando una amplia biografía de Jerónimo de Ayanz.

(35) Sobre la actividad de Jerónimo de Ayanz como pintor, Nicolás García TAPIA, "Nobleza, pintura e invención. ¿Jerónimo de Ayanz pintor?" en Homenaje al Dr. Juan José Martín González. Universidad de Valladolid, en prensa. 
Sin embargo, no lo traemos aquí por sus proezas militares o artísticas, sino por las de científico, técnico e inventor, en las cuales sobresalió de forma extraordinaria. Como hombre de ciencia, intervino en el problema de la determinación de la longitud en alta mar, que entonces era una gran preocupación para aquellos que hacían la Carrera de las Indias. La solución no era posible en la época de Ayanz a causa de la falta de un reloj que pudiese medir el tiempo de forma precisa en alta mar. Lo que hizo Ayanz fue denunciar la falsedad de algunos de los métodos que entonces se propusieron (36). Como técnico, hizo una minuciosa visita a las minas españolas, en su cargo de administrador general de las minas del Reino, haciendo ensayos metalúrgicos y proponiendo soluciones para beneficiar los minerales, entre ellos los famosos "negrillos" del Potosí, para obtener de ellos la plata. Como inventor, obtuvo privilegios para más de cincuenta invenciones, todas ellas de un extraordinario interés, no sólo en el campo de la minería, sino en los de la mecánica, maquinaria, molinos, procesos industriales, instrumentos, máquinas, herramientas, etc., que hacen de Ayanz un nuevo Leonardo da Vinci, sin exageración de ningún tipo. Baste decir que patentó las primeras máquinas de vapor conocidas, las cuales se adelantaron en un siglo a las similares inglesas de Savery que dieron origen a la revolución industrial (37).

Volviendo a los equipos de buceo, y después de la satisfactoria prueba que Ayanz realizó ante el Rey, se le concedieron dos reales cédulas en 1603 y en 1605, otorgándole un privilegio de explotación de sus invenciones para todos los reinos españoles, incluidos los de América, durante un período de veinte años (38).

Ayanz criticó las campanas de buceo tradicionales y en particular la inventada por José Bono, a la que considera un fraude, ya que, aparte de ser una copia de algo que se conocía ya desde época romana, presenta muchos inconvenientes por el peligro de vuelco debido al oleaje del mar y a la presión del aire en el interior de la campana, lo que causaba que muchos buzos se ahogasen. Por otra parte, la falta de renovación del aire en su

(36) Nicolás GARcfa TAPIA, "Los ingenieros y la Cosmografía en España en los siglos XVI y XVI", en Mundialización de la ciencia y cultura nacional, A. LAFUeNTE, A. Elena y M. OrTEga (Eds.), Universidad Autónoma de Madrid, Aranjuez, 1993, págs. 97-104.

(37) Idem. "Some Design of Jerónimo de Ayanz (C. 1550-1613). Relating to Mining, Metallurgy and Steam Pumps", History of Technology, 14, 1992, págs. 135-150.

(38) AGS, Cámara de Castilla, Libro de Cédula n 174, fols. 49-94. Reproducción facsímil y comentarios en GARCía TAPIA, [1], págs. 61-256. 
interior, suponía que la estancia de un hombre allí sin peligro de muerte por asfixia, quedase limitada a unos veinte minutos, no por el tiempo ilimitado que anunciaba José Bono. Por este motivo, Ayanz entabló una dura polémica con el inventor italiano, singularmente por la exclusiva que pretendía para usar sus aparatos de buceo en las pesquerías de perlas de la isla Margarita. Ayanz consiguió anular el privilegio de Bono y que se le aplicase de parte la sanción requerida para este caso. También pleiteó Ayanz con un hombre que había intentando copiar su instrumento "torciendo un caño o añadiendo otra cosa", con lo que pretendía que era diferente al de Ayanz, manifestando además, con engaño, que tenía un poder de Ayanz para usarlos. Este falso inventor se había puesto en contacto en Sevilla con indianos para llevar estos instrumentos plagiados a América (39). Los intentos de copiar los equipos de buceo que había inventado Ayanz, es una prueba más del éxito que habían alcanzado.

La solución propuesta por Ayanz fue la de los equipos de buceo autónomos provistos de todos los elementos necesarios para la renovación de aire, que eran un precedente de los que se usan actualmente. La diferencia está en el suministro de aire, que ahora se hace por compresores o botellas de oxígeno a presión, y que Ayanz lo resolvió por fuelles manuales o por odres rellenos de aire. Los conductos eran tramos de tubos de cobre o de bronce, con uniones flexibles de cuero, que conectaban los fuelles a unas boquillas que se ataban los buzos a la cabeza, en las que hay unas válvulas para la aspiración y la expulsión de aire, complementados con trajes de bucear realizados con cueros vacunos (40). Con semejantes artificios, pudo hacer la prueba con éxito en el río Pisuerga de Valladolid, permaneciendo por primera vez los buceadores más de una hora bajo el agua, aunque a los pocos metros de profundidad que tiene el río vallisoletano. Faltaba probar los aparatos a mayores profundidades bajo el mar. Estos instrumentos aparecen dibujados en unos planos conservados en el Archivo General de Indias de Sevilla (Fig. 4), junto con una patente de invención fechada el 20 de junio de 1605, concedida por el rey en Valladolid (41).

Ayanz dedicó algún tiempo más a perfeccionar sus aparatos. El 1 de septiembre de 1606 consiguió una patente por más de cincuenta invenciones, entre los que se encuentran nuevos mo-

(39) Garcia TaPia, [6], pág. 313. AGI, Patronato, leg. 171, no 1, ramo 37.

(40) Idem., Patentes..., op. cit., págs. 94-97.

(41) AGI, Mapas y Planos, Ingenios y Máquinas, $n^{\circ}$ 5. Leg. 171, n 1, ramo 37. 
delos de aparatos de bucear, con sus correspondientes dibujos. Este importante documento se conserva en el archivo de Simancas y no había sido estudiado hasta que lo hemos descubierto en fecha reciente. El análisis de su contenido, revela que los defectos que se habían observado en las pruebas realizadas, quedan ahora solucionados, y además se proponen otros nuevos sistemas de submersión (Fig. 5 y 6).

Jerónimo de Ayanz divide su exposición de los aparatos de buceo en nueve capítulos que corresponden a cada uno de los sistemas que propone para que un hombre pueda estar bajo el agua. Dado que su descripción es muy detallada y ya la hemos publicado integra (42), nos limitaremos aquí a resumir los capítulos:

En el primero, Ayanz propone la utilización de dos conductos articulados para permitir el desplazamiento del buzo, uno de ellos recibe el aire de unos fuelles y por el otro se expulsa el aire viciado. El buzo respira por medio de una boquilla que se sujeta a la nariz o a la boca.

En el segundo capítulo se presenta una variante del equipo anterior, con los dos tubos sujetos a unos flotadores.

En el tercer capítulo, se sustituye el tubo de expulsión del aire por una válvula de escape situada en el interior de una pequeña campana.

En el cuarto capítulo se presenta cómo debe ser realmente una campana de bucear para que un hombre pueda estar en el interior sin peligro y por tiempo indefinido. Para ello, el aire ocluido en la campana se renueva por medio de dos tubos flexibles y unos fuelles que permiten introducir el aire a través de una válvula de aspiración y expulsar el aire viciado por la correspondiente válvula de escape. La campana tiene unas patas que permite posarla en el fondo y sujetarla con pesos para evitar los vaivenes del mar.

Los capítulos quinto y sexto están dedicados a los dibujos y descripción de dos modelos de barcas submarinas, calafateadas interiormente y totalmente cerradas. El aire se renueva en su interior por unos fuelles y unos tubos, como los de los equipos de buceo, terminados en válvulas de aspiración y escape. Incluso, los ocupantes pueden respirar un aire agradable, ya que en el interior hay unos ventiladores que se mueven por unas velas exteriores que giran con la corriente del agua. El aire, así esparcido, es filtrado a través de unas esponjas impregnadas de agua de rosas. Para poder sumergir las barcas, éstas van provistas un

(42) García TaPia, [1], págs. 225-238. 

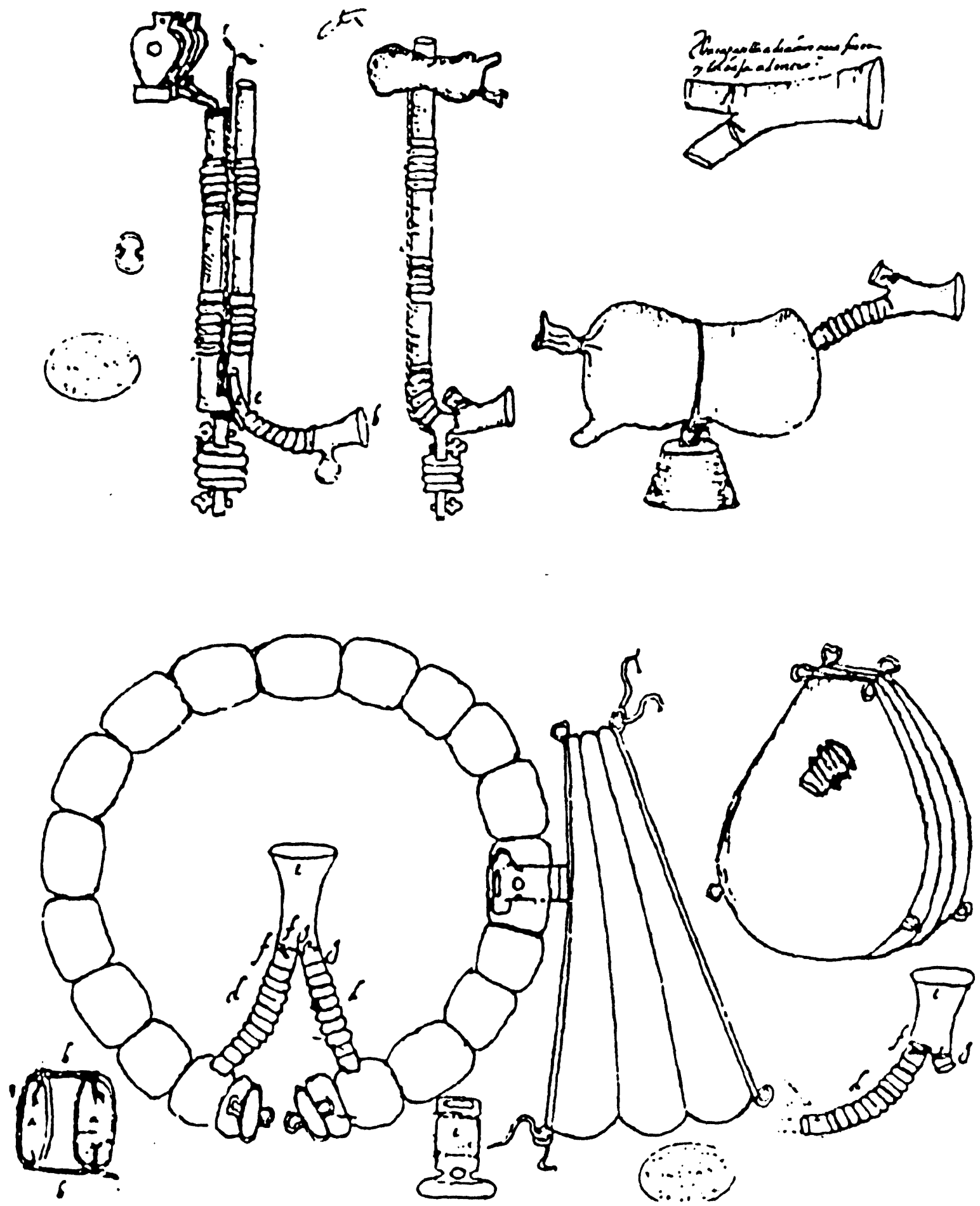

Fig. 4. Jerónimo de Ayanz. Equipos de buceo. (Archivo General de Indias de Sevilla). 


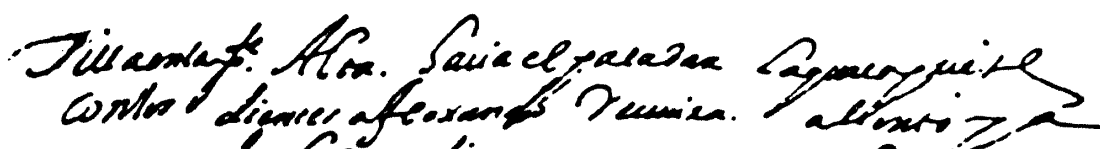

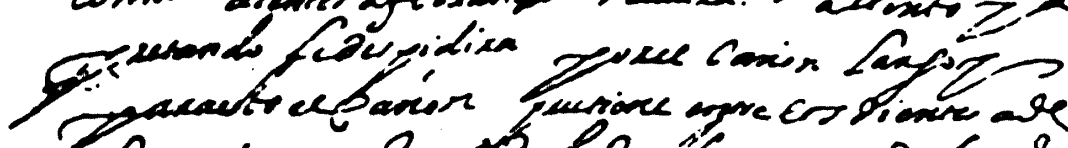

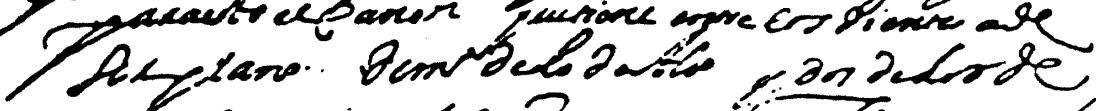

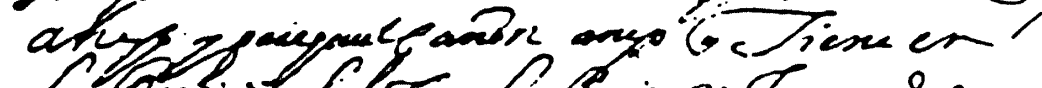

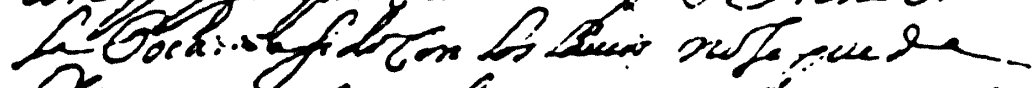

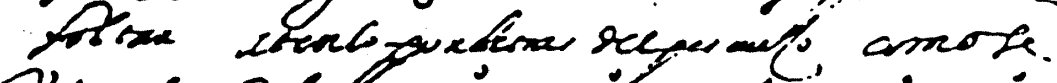

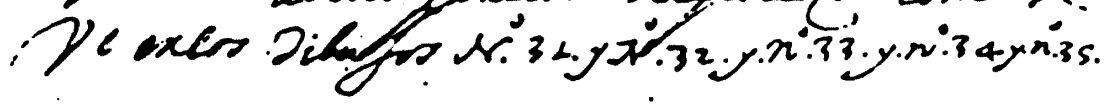
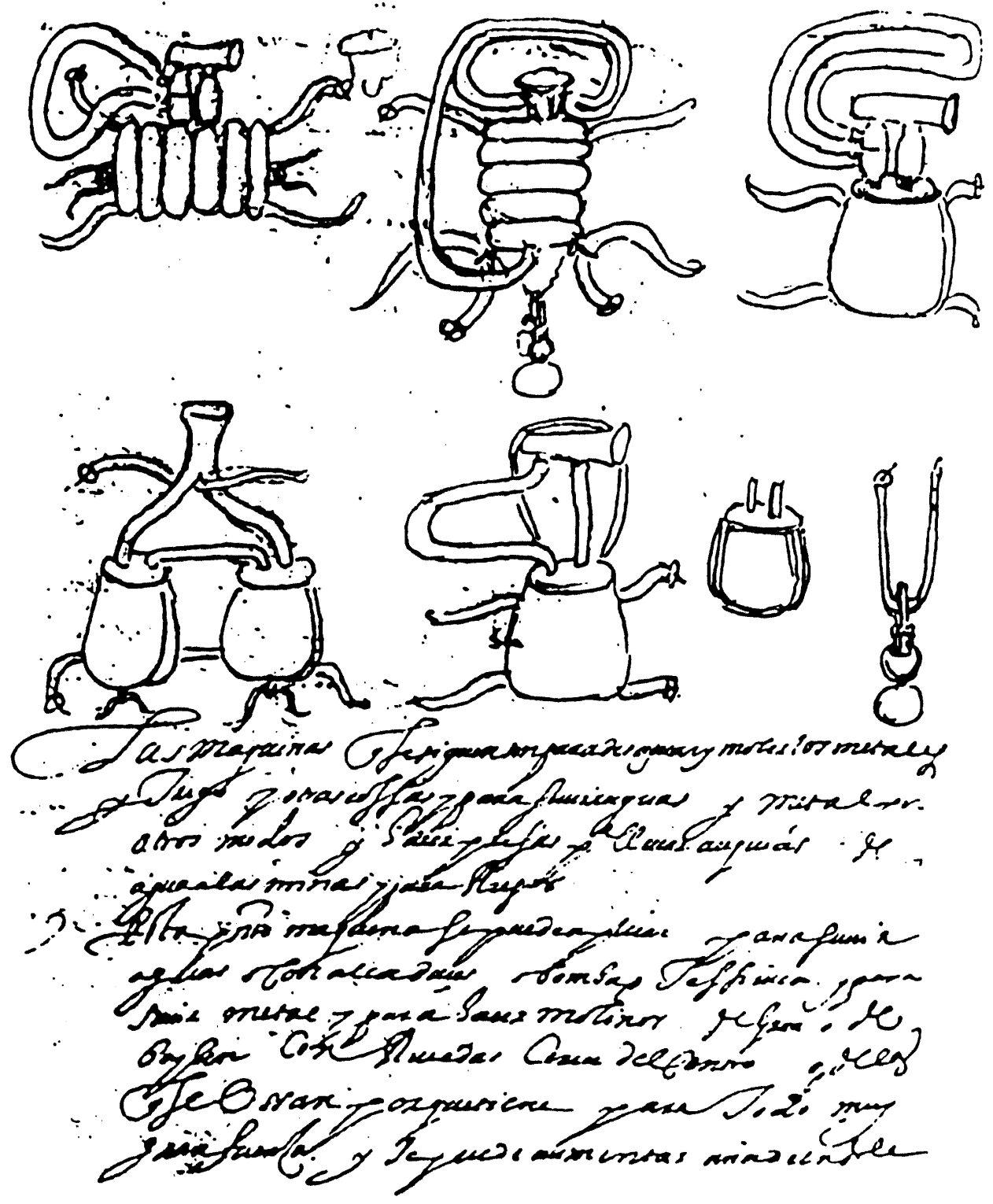

Fig. 5. Jerónimo de Ayanz. Barca-submarino. (Archivo General de Simancas). 


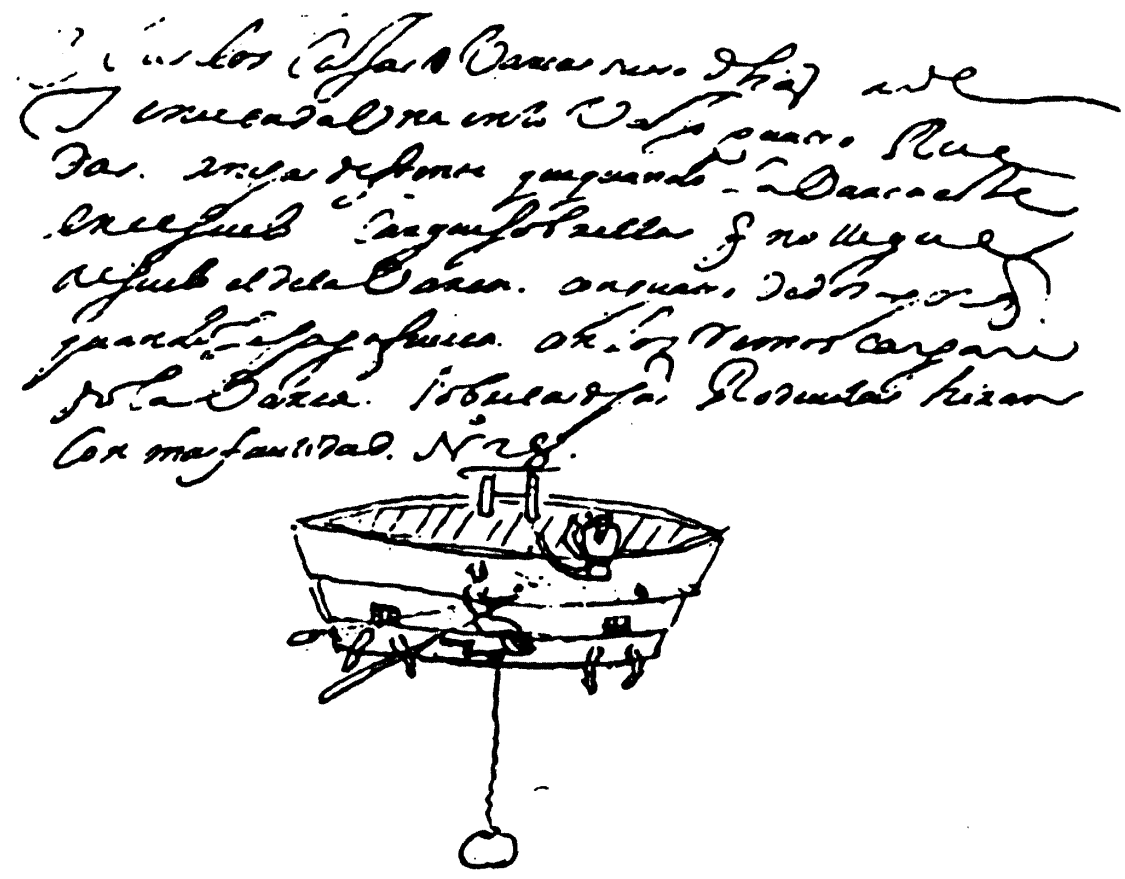

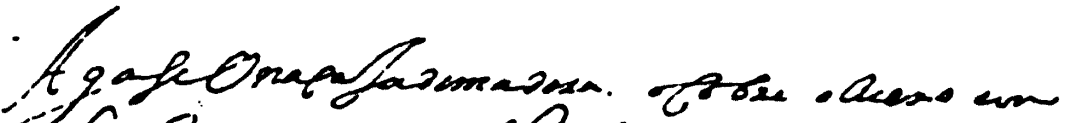

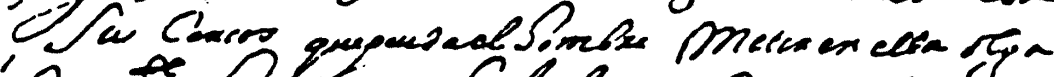

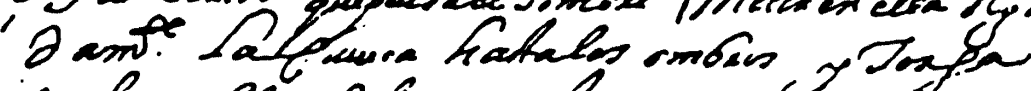

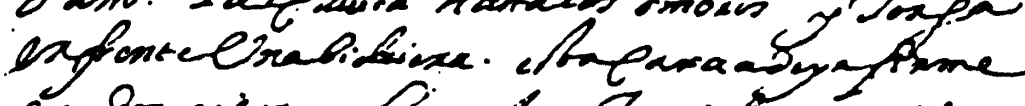

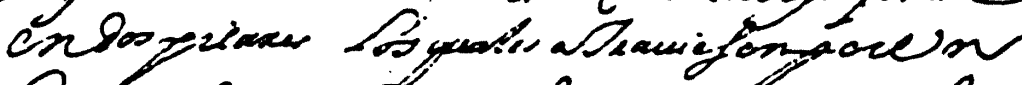

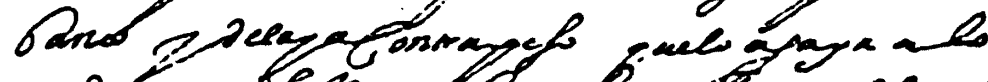

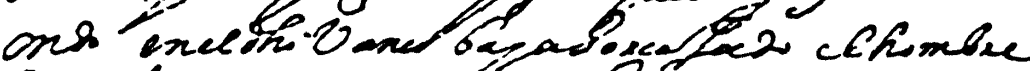

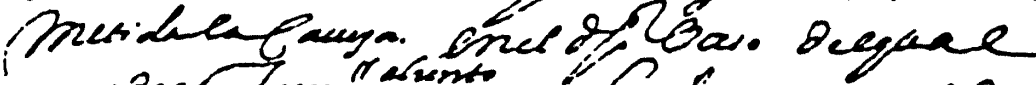

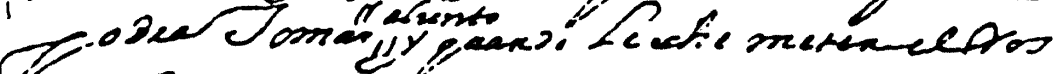

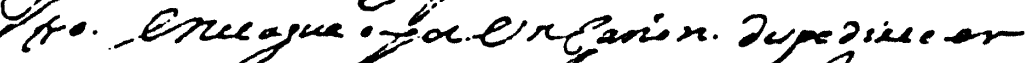

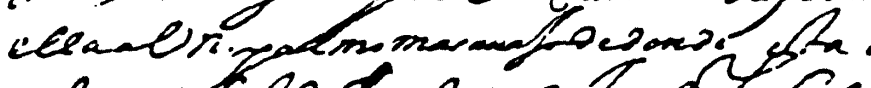

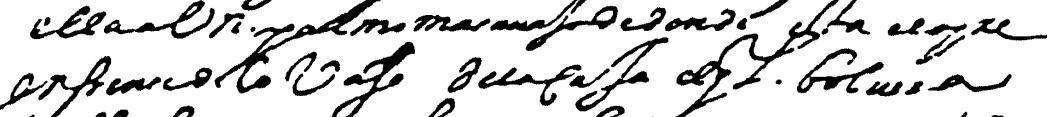

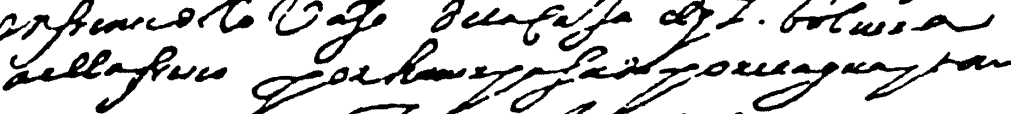

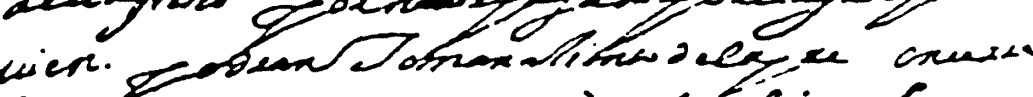

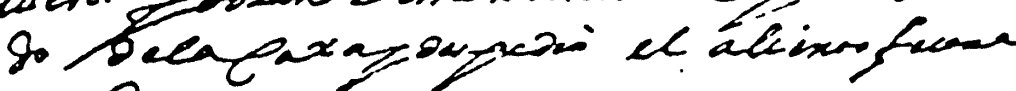

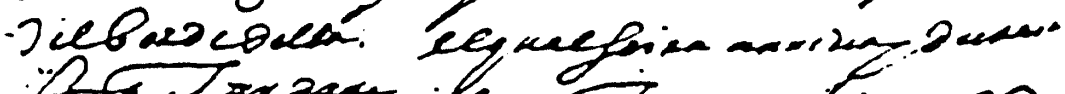

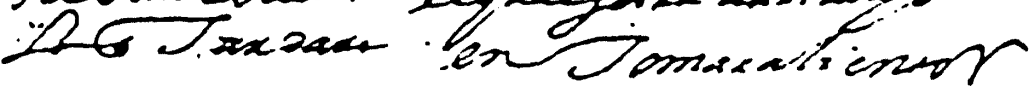

FIG. 6. Jerónimo de Ayanz. Equipos de buceo autónomos. (Archivo General de Simancas). 
lastre con un contrapeso que puede alzarse con un torno desde el interior, en el cual pueden ir dos personas. En los costados de la barca hay dos ventanas protegidas con rejas y unas mangueras por las que los submarinistas pueden introducir los brazos para recoger los productos que vean por las ventanas, depositándolos en sendos compartimentos que se encuentran en el exterior. Incluso estaba previsto colocar unas ruedas a la barca para que pueda desplazarse por el fondo, con la ayuda de unos remos manejados por los hombres desde el interior. Se convertiría así en una base de operaciones para la búsqueda de todo tipo de tesoros bajo el mar. Ni que decir tiene la repercusión que hubiera tenido la invención de este submarino de llegarse a realizar. Lo único que puede aducirse, es que fue prematuramente diseñado por Ayanz con respecto a las posibilidades tecnológicas de su tiempo, que sin duda impidieron el desarrollo de una idea que, básicamente, es la que varios siglos después, con unas nuevas posibilidades técnicas, se aplicaría a los submarinos que ahora conocemos. En todo caso, es la primera patente conocida en el mundo de un submarino.

En el capítulo séptimo, Ayanz presenta una escafandra para bucear, con su equipo de fuelles y válvulas para renovar el aire y que se complementa con un traje de cuero impermeabilizado para poder sumergirse incluso en aguas muy frías.

Más primitivo parece el sistema de bucear del capítulo octavo, que permite que un hombre vaya sumergido a caballo sobre un cuero hinchado, respirando el aire contenido en él por medio de un conducto provisto de válvulas de aspiración y expulsión y una boquilla para respirar.

Finalmente, en el capítulo noveno se presentan una serie de equipos autónomos de buceo en los que el buzo puede sumergirse sin necesidad de ayuda exterior, ni de conductos que le unan a la superficie. El hombre lleva atado, en la espalda o en el pecho, unos ingeniosos fuelles que puede accionar con los brazos o con la cabeza, lo que le permite respirar a través de unas válvulas y unas boquillas sujetas a la nuca. El buzo es así libre para nadar y manejarse bajo el agua, como con los modernos equipos de bucear.

\section{UNA INVENCIÓN OLVIDADA DURANTE SIGLOS}

La principal intención de Jerónimo de Ayanz, como había sido antes la de su rival Bono, fue la de utilizar estos instrumentos 
de buceo en el rescate de los tesoros de los barcos hundidos y en la explotación de las riquezas perlíferas americanas, principalmente las de la isla Margarita (43). Sin embargo, después de obtenida la patente de 1606, no tenemos noticias de que Ayanz intentase probar estos aparatos de bucear en América, por lo que desconocemos si tuvieron la aplicación deseada. El inventor se dedicó a otras actividades relacionadas con la minería y la cosmografía. Siendo ya su salud muy deficiente para hacer sus pruebas en América, Jerónimo de Ayanz murió en 1613, cuando aún no había prescrito su privilegio de invención. Este pasó a su hija Josefa de Ayanz y luego a su sobrino Jerónimo de Ayanz y Javier, quien, siguiendo la tónica que caracterizó a la mayoría de la nobleza española del siglo XVII, trató de subir en lo que era meramente honorífico, acumulado los títulos de caballero de la Orden de Calatrava, gentilhombre de boca, contador mayor de la hacienda del Rey, primer caballerizo de la Reina y capitán de remisionados del Reino. Con todo ello, olvidó por completo los sueños que su tío había hecho realidad: entre otras cosas, dominar el vapor en una máquina y hacer que un hombre pudiese estar por tiempo indefinido bajo el agua y poder así rescatar los tesoros escondidos en el mar.

(43) AGP, cajas 87/84 y 87/49. García TAPIA, [33], pág. 224. 